\title{
The importance of dynamic topography for understanding past sea-level changes
}

Jacqueline Austermann ${ }^{1}$ and Alessandro M. Forte ${ }^{2}$

\author{
Mantle flow pushes Earth's surface up or drags it down, causing kilometer-scale topographic anomalies. As this \\ so-called "dynamic topography" evolves, it can influence local sea level and the sensitivity of ice sheets to climate \\ change.
}

Local sea-level reconstructions have been the foundation for understanding past icesheet behavior, especially records spanning the last deglaciation and past interglacial periods. Linking the evolution of local sea level to global mean sea level, which is also related to ice-volume changes, requires a correction for any uplift or subsidence of the field site that has occurred since the sea-level record was formed. Such vertical movements can occur due to tectonic crustal deformation, glacial isostatic adjustment (GIA; e.g. Milne et al. this issue), erosion, or sediment loading (e.g. Ferrier et al. this issue).

Another process that shapes Earth's surface is dynamic topography, which is the topography generated by vertical forces arising from buoyancy-induced flow within the Earth's mantle (Fig. 1). While this process was first recognized decades ago, the full extent to which dynamic topography affects sea-level records over the Plio-Pleistocene and interacts with the Earth climate system as a whole (e.g. ice sheets and oceans) has only recently been explored.

\section{Definition of mantle dynamic topography} Today's surface topography is shaped by crustal isostasy, in which, for example, crustal roots support mountain belts, and dynamic topography, which is driven by stresses in the sub-crustal mantle that are caused by (shallow) isostatic and (deeper) flow-driven contributions (Forte et al. 1993). Both of these components evolve with time as lateral density variations in the sub-crustal mantle convect and cool the rocky mantle. This leads to spatio-temporal changes in dynamic topography that contribute to the evolution of Earth's surface.

While convection extends from the lithosphere to the core-mantle boundary, sensitivity studies reveal that density heterogeneity in the shallow mantle (e.g. the lithosphere and asthenosphere) contributes most to the overall topographic signal (Forte et al. 2015). The definition of dynamic topography used here includes the topographic signature of the lithosphere (e.g. cooling and subsidence of the oceanic lithosphere), as it constitutes the upper thermal-boundary layer of Earth's convective interior. However, it is important to note that a lithospheric signal is sometimes removed from models or observations in order to investigate sub-lithospheric or deep-mantle drivers of surface topography.

\section{Present-day dynamic topography}

Estimates of present-day dynamic topography can be obtained by removing the crustal isostatic effect from the observed topography, which requires knowledge of the crustal thickness and density, as well as overlying sediment, water, and ice loads. Global estimates of dynamic topog raphy reveal large-scale undulations with magnitudes that exceed $2 \mathrm{~km}$ (Forte et al. 2015). Within the oceans, a detailed assessment has shown that the sub-lithospheric contribution to dynamic topography has a magnitude that ranges from approx. $-1.5 \mathrm{~km}$
(Australia-Antarctic discordance) to $2 \mathrm{~km}$ (around Iceland) and can have steep lateral gradients (e.g. $1 \mathrm{~km}$ of dynamic topography change over a lateral distance of $1000 \mathrm{~km}$ along the West African Margin; Hoggard et al. 2016).

These observations of dynamic topography can be used to improve numerical models of mantle convection and understand the dynamics of the Earth's interior. Models of present-day mantle convection require an input density field of the Earth's interior (estimated from seismic tomography), a rheological constitutive equation that describes the relationship between deformation and stress, and boundary conditions, which govern the tangential stresses at the surface and core-mantle boundary. Assuming conservation of mass and momentum, one can determine the instantaneous velocity and dynamic stress fields (Forte et al. 2015). The resulting dynamic topography is calculated by balancing radial stresses at the Earth's surface (Fig. 1). Current mantle convection models provide satisfactory fits to the present-day observations of dynamic topography and gravity anomalies (Simmons et al. 2010); however, debate over the largest and small-scale features still exists (Hoggard et al. 2016).

\section{Changes of dynamic topography}

To understand the role of dynamic topog raphy in sea-level reconstructions, we are interested in the temporal evolution of dynamic topography, rather than its absolute

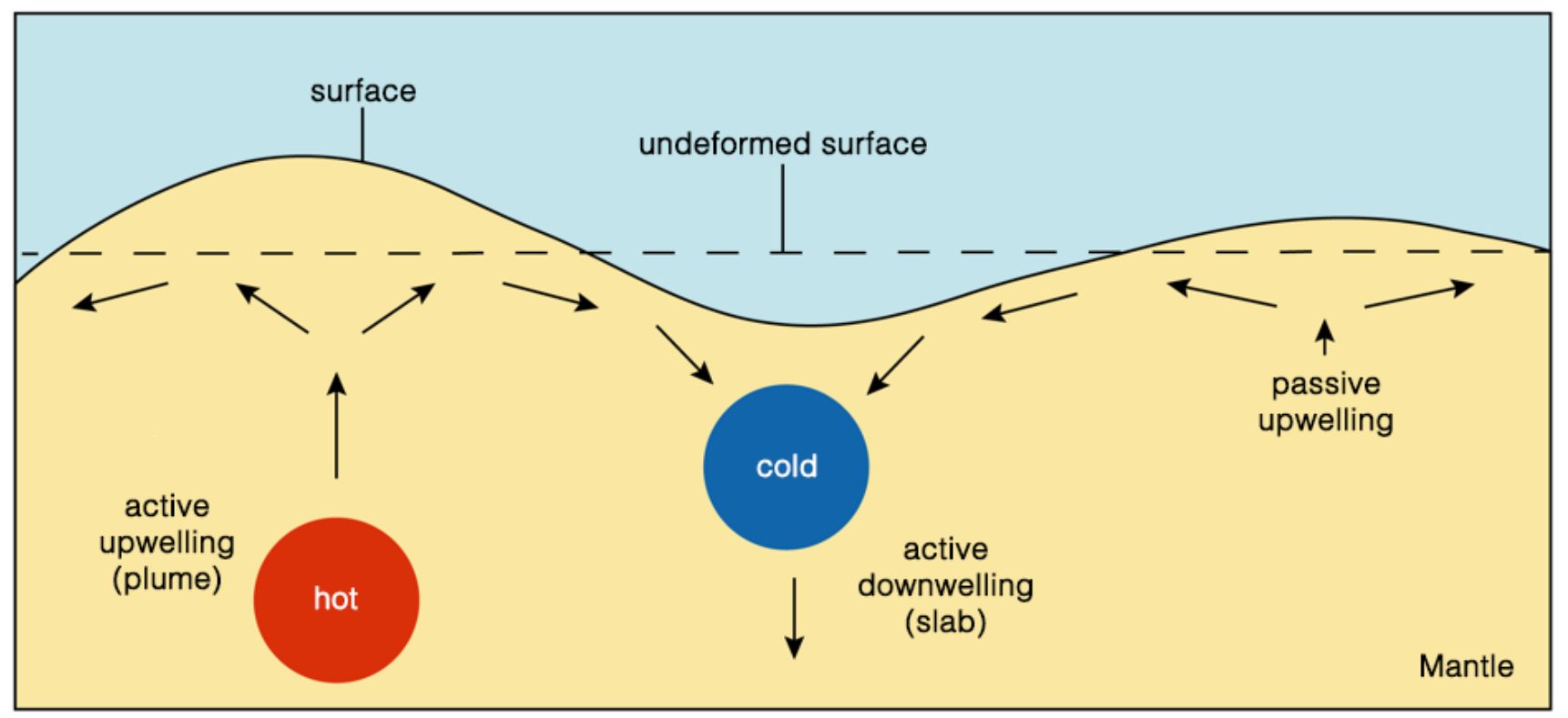

Figure 1: Illustration of how flow in the mantle can generate dynamic surface topography (modified from R. Moucha, personal communication). 

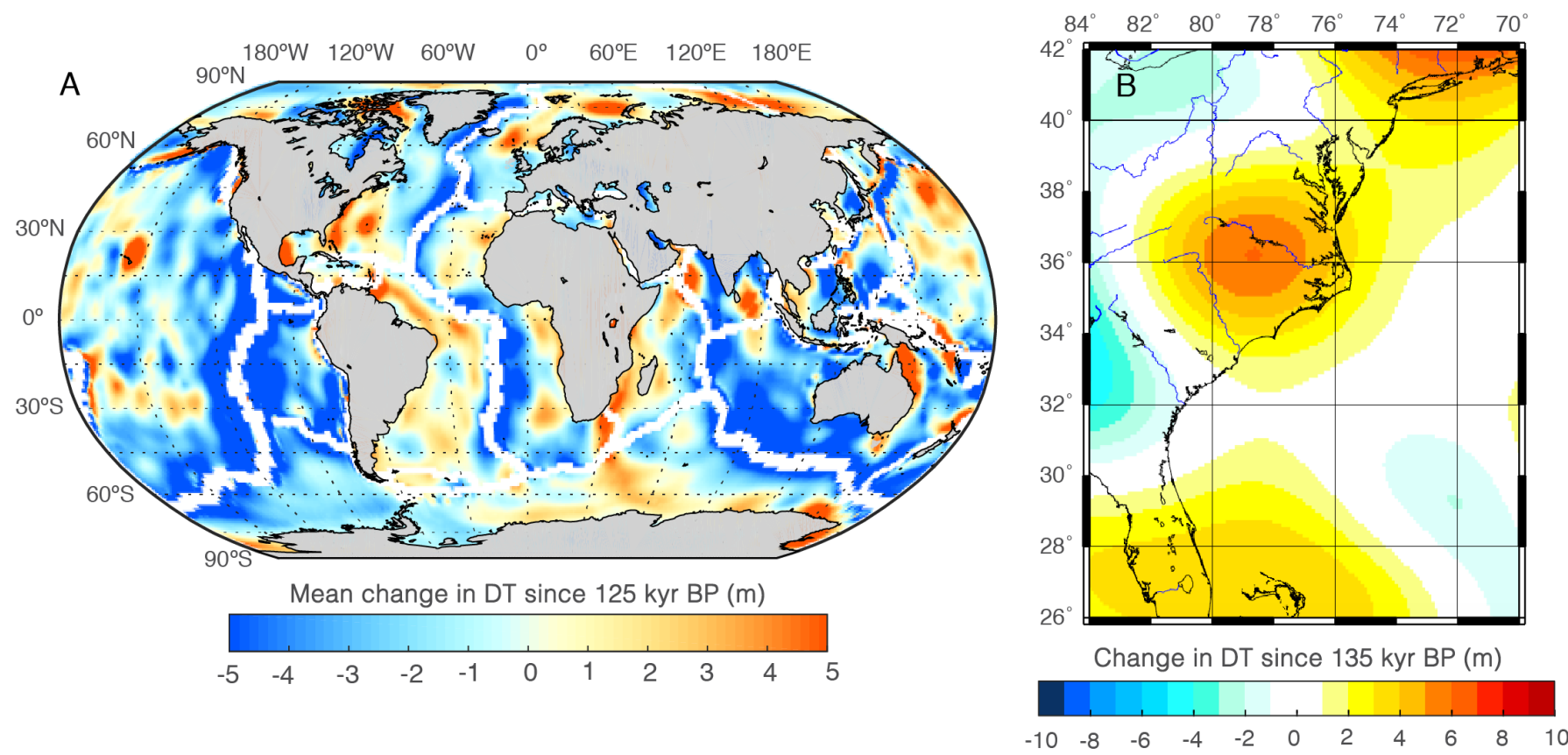

Figure 2: Model results of dynamic topography (DT) change since the last interglacial period from (A) the mean of 12 different models (Austermann et al. 2017) and (B) one preferred model scenario for the US east coast (Dutton and Forte 2016) based on mantle convection reconstructions by Glišović and Forte (2016).

(present-day) value. Importantly, present-day amplitudes do not provide information on the change of dynamic topography through time. For example, locations that are dynamically supported today are equally likely to be uplifting or subsiding.

Changes in dynamic topography can be deduced from a variety of geological and geomorphological data. For example, a careful analysis of stratigraphy from onshore and offshore Australia indicates changes in dynamic topography (subsidence) of up to $75 \mathrm{~m} /$ Myr on the Northwest Shelf (Czarnota et al. 2013). Paleo shorelines from the US east coast, Australia, and South Africa indicate rates of uplift of up to $20 \mathrm{~m} / \mathrm{Myr}$ (Rovere et al. 2014). Model-derived estimates of the rate of change in dynamic topography can vary from a few meters per million years (Flament et al. 2013) up to over $100 \mathrm{~m}$ per million years (Rowley et al. 2013; Austermann et al. 2017) depending on the model input parameters, particularly the viscosity structure, magnitude of density perturbations, and whether density variations in the asthenosphere and lithosphere are considered.

\section{The contribution of dynamic topography} to past sea-level and ice-sheet changes Initial indications that dynamic topography can cause local sea-level changes stems from observations and modeling work on continental flooding histories over the Phanerozoic (Bond 1979; Gurnis 1993). It is now recognized that local paleo sea-level reconstructions, whether from continental flooding, backstripping at passive margins, or stratigraphy in sedimentary basins, are not equal to global mean sea-level change, due to regionally varying changes in dynamic topography (Moucha et al. 2008). This limitation also applies to the more recent past of the Plio-Pleistocene.

Mapping of Pliocene shorelines shows significant variations in their elevations relative to one another and along the shoreline feature
(Rovere et al. 2014). The most prominent example is the Orangeburg Scarp along the US east coast, which exhibits a change in elevation of up to $40 \mathrm{~m}$ after correcting for glacial isostatic adjustment. Rowley et al. (2013) have shown that this relative deformation can be explained by changes in dynamic topography. However, uncertainties in input parameters for numerical models of dynamic topography, as well as an incomplete understanding of the contribution of competing deformation processes, such as sediment loading, still hinder a quantification of global mean sea level and, hence, ice-sheet stability during this time period. This work prompted a re-examination of sea-level records from earlier interglacials. Model predictions indicate that dynamic topography can contribute up to several meters of deformation to local sea-level records dating to the last interglacial period (Fig. 2). This modeling is corroborated by a significant correlation between the predicted deformation and the observed elevations of sea-level indicators from the last interglacial (Austermann et al. 2017). Estimates of excess global mean sea level during this time period are 6-9 m (Dutton et al. 2015), which does not account for dynamic topography. If key sites have been affected by changes in dynamic topography, this 6-9 m estimate could be incorrect by a few meters. Improving estimates of global mean sea level and ice-sheet stability during past interglacials therefore hinges on a better understanding of dynamic topography.

Mantle flow underneath ice sheets can also directly affect ice-sheet evolution. For example, dynamic topography changes along the grounding line of the Antarctic Wilkes Basin potentially made this sector more susceptible to retreat in the Pliocene epoch (Austermann et al. 2015).

Mantle flow directly affects sea-level records, ice-sheet behavior, and ocean dynamics, which has led to intriguing new links between the solid Earth and the climate system. This nascent connection provides promising avenues to potentially answer some open questions in paleoclimate research, as well as the opportunity to expand observational constraints on the structure and dynamics of Earth's deep interior.

\section{ACKNOWLEDGEMENTS}

We would like to thank A. Dutton and M. Hoggard for many helpful discussions. AMF acknowledges support provided by the University of Florida and thanks P. Glisovic (GEOTOP, UQAM) for his contributions and for support from the Natural Sciences and Engineering Research Council of Canada and Calcul Québec.

\section{AFFILIATIONS}

'Lamont-Doherty Earth Observatory, Columbia University, New York City, USA

${ }^{2}$ Department of Geological Sciences, University of Florida, Gainesville, USA

\section{CONTACT}

Jacqueline Austermann: ja3170@columbia.edu

\section{REFERENCES}

Austermann J et al. (2015) Geology 43 : 927-930

Austermann J et al. (2017) Science Advances 3: e1700457

Bond GC (1979) Tectonophysics 61: 285-305

Czarnota Ket al. (2013) Geochem Geophy Geosy 14: 634-658

Dutton A et al. (2015) Science 349: aaa4019

Dutton A, Forte A (2016) AGU Fall Meeting, PP51B-2309 Flament $\mathrm{N}$ et al. (2013) Lithosphere 5: 189-210

Forte A et al. (2015) in: Romanowicz B, Dziewonski A (Eds) Treatise of Geophysics, Volume 1: Deep Earth Seismology, Elsevier, 853-907

Forte AM et al. (1993) Geophys Res Lett 20: 225-228 Glišović P, Forte AM (2016) J Geophys Res: Solid Earth $121,4067-4084$

Gurnis M (1993) Nature 364: 589-593

Hoggard M et al. (2016) Nat Geosci 9: 456-463 Moucha R et al. (2008) Earth Planet Sci Lett 271: 101-108 Rovere A et al. (2014) Earth Planet Sci Lett 387: 27-33 